\title{
Development of technology for production of fire-resistant nanocomposite constructional rebar and structural elements based on it
}

\author{
Andrey Ponomarev ${ }^{1,2}$, Daria Steshenko ${ }^{1 *}$, Aleksandr Rassokhin ${ }^{1,2}$ \\ ${ }^{1}$ Peter the Great St. Petersburg Polytechnic University, 29 Politekhnicheskaya Street, Saint- \\ Petersburg, 195251, Russian Federation \\ ${ }^{2}$ People Friendship University of Russia (RUDN University)
}

\begin{abstract}
Analysis of recent publications describing the situation with fiber-reinforced plastic rebar is contained in the paper. The available types of composite reinforcement have a number of advantages, but also have significant drawbacks. New technical developments and fresh ideas, born thanks to the integration of sciences, make it possible to begin the creation of a technology for the production of fundamentally new types of rebar based on an inorganic (mineral) binder. New rebar will be tough and resistant to fire and high temperatures.
\end{abstract}

\section{Introduction}

\subsection{Description of the problem}

The experience of using fibre-reinforced plastic rebar (FRP rebar) in the construction of the last decades revealed many positive advantages (lightness, durability, high corrosion resistance in many environments), but also showed intractable deficiencies:

- difference in the values of elastic moduli of a polymer matrix based on polyester resins (especially even with insignificant heating) and reinforced concrete creates difficulties in ensuring the joint operation of reinforced FRP concrete structures;

- the low value of the glass transition temperature of polymeric matrices of FRF (120$150^{\circ} \mathrm{C}$ ) seriously narrows the range of applicability, and in some cases significantly reduces the level of safety of buildings and structures created with its use;

Steel structural and reinforcing elements, as well as new polymer composite materials are based on fossil ore and organic raw materials, the reserves of which are finite. In the coming decades, the gradual reduction of their production will inevitably lead to with a rise in the cost of the products [1].

At the same time, the requirements for the safety of buildings, especially for fire safety, are becoming increasingly stringent.

\footnotetext{
* Corresponding author: steshenko.dyu@edu.spbstu.ru
} 


\subsection{Review}

The enormous amount of concrete production has a serious impact on energy, resources, environment and ecosystem. Therefore, the issue of development of sustainable concrete technology with little impact on the environment is becoming a major issue. Researches related with sustainable development of concrete are presented in last three decades in conference paper by J. Sim, M.Ju, K. Lee [2].

The last experimental work for the study of high-performance concrete in composite steel and concrete structures allowed to describe the nature of the destruction of models of combined structures and compare the values of strength and displacement with the normalized values $[3,4]$. Also, researchers from Russia studied the possibilities of reinforcing concrete with synthetic fibers [5] and modifying concrete by various additives [6], as well as they studied the possibility of optimizing the composition of modified fine-grained concrete fiber with carbon nanostructures [7]. In the field of composite reinforcement, a numerical model for estimating the effect of composite reinforcement on the bearing capacity of a compressed-bent masonry wall which is constructed on the basis of experimental studies of walls from cellular concrete blocks, was proposed [8].

The results from a survey, which was conducted to evaluate over 20 international FRP rebar manufacturers and their production processes, was presented. The ongoing survey was designed to identify manufacturing trends, as well as production sequencing and planning. In addition, the existing guidelines and material specifications for FRP rebar around the world were identified and summarized. The demand for FRP rebar are in an upward trend in the US and Canada according to the survey. Initial observations confirmed that the composite rebar market is dispersed, without consensus on the manufacturing process or standardization requirements. FRP rebar manufacturers have developed different composite rebar types, that are made from various constituents, with an array of geometries and surface enhancements. This study, as part of a larger research project on composite rebar, compiles and centralizes this information and aims to establish a database of global composite rebar manufacturers to provide a resource for all stakeholders involved in the construction industry [9].

Recognition and multiple applications of composites are important in many countries. Scientists from Iran recognize that light weight and resistance to corrosion are the main advantages of FRP rebar [10]. Canadian researchers also study the durability of FRP in aggressive environments and believe that the lack of serious research is an obstacle to the massive introduction of this rebar [11].

Further, the researchers studied the joint work of concrete and various types of FRP [12], evaluated the effect of friction, adhesion and mechanical bonding on the strength of the bonds between FRP and concrete [13].

Another important area of research is the fire resistance of structures with FRP [13]. Kodur V.K.R. and Bhatt PP. suggest a numerical approach for the correct evaluation of the operation of structures with FRF under the influence of fire [14]. Turkish and british [15] researchers conducted tests comparing the behavior of steel reinforcement and FRF under the influence of fire [16]. Chinese researchers conducted a series of large-scale experiments with GFRP and showed the disadvantages of this type of rebar [17]. New types of composite reinforcement appear daily, but each type has the same disadvantages [18].

Thus, the necessity to find ways to develop rigid and fire-resistant inorganic matrices for rebar becomes understandable. A new reinforcement based on an inorganic binder should not have the disadvantages of a fibre-reinforced plastic rebar. At present, intensive research is devoted to this area [19].

At the border of 2009-2010, researchers from Russia discovered a progressive way to solve the task. They decided to use a new fundamental phenomenon of the giant resonant amplification of an external electromagnetic field near the surface of toroidal nonmetallic particles [20]. This phenomenon is realized on polyhedral multilayer carbon nanostructures 
of toroidal type - «astralenes» [21]. Patents of the Russian Federation №2397950, USA Patent № US 9090 72, China ZL 200980160650X protect the invention. A deeper study of the unusual properties of astralenes continued in Russia and Israel [22]. The introduction of astralenes (produced by the Scientific and Technical Center «Applied Nanotechnologies», St. Petersburg) into various composite material leads to condensation of interface boundaries, including in compositions based on various mineral binders (for example, in concretes and other materials based on inorganic binders). It comes due to the use of the giant Van der Waals interaction arising at the modified interphase boundaries. This technique significantly reduces the requirements for subsequent pressing and heat treatment regimes of such «nanocomposite» materials [23-26].

\subsection{Formulation of research tasks}

On the basis of high-modulus fibers and inorganic matrix, need to create a fire-resistant composite rebar with a new mineral binder, produced by the widespread pultrusion technology.

The technology should allow the use of existing lines for the pultrusion manufacturing of fibre-reinforced plastic rebar for the transition to the release of a new product - fireresistant nanocomposite rebar based on inorganic binders. The main parameters of fireresistant nanocomposite rebar for use in construction and engineering do not change and comply with current state standards for size and physical and mechanical characteristics. However, the three characteristics change considerably:

- the combustibility class of the rebar will change from the category «G2-G1» to «NG»;

- heat resistance will rise to above $500^{\circ} \mathrm{C}$;

- the values of the elastic modulus of the binder should not be lower than the elastic modulus of industrial structural concrete (for example, concrete grade B60) - $40 \mathrm{GPa}$.

- the developed technology will allow the industry to produce nanocomposite rebar. It will have a strength characteristics and price comparable to steel, but it will exceed steel rebar in corrosion and thermal resistance.

- the developing the constructions of the plane grating fire resistant rebars for the railway aleepers.

\subsection{Scientific groundwork}

At the moment, complex studies of a block of light nanostructured concrete reinforced bulk grating which is made of flat fiberglass elements were carried out.

Plate strength measurements in a four-point bend were carried out according to GOST 16483.12-72. The tests were carried out at the stand with a hydraulic test module BISS MAGNUM UT-05-3000.

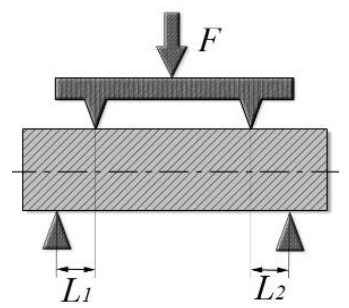

Fig. 1. Test scheme. 


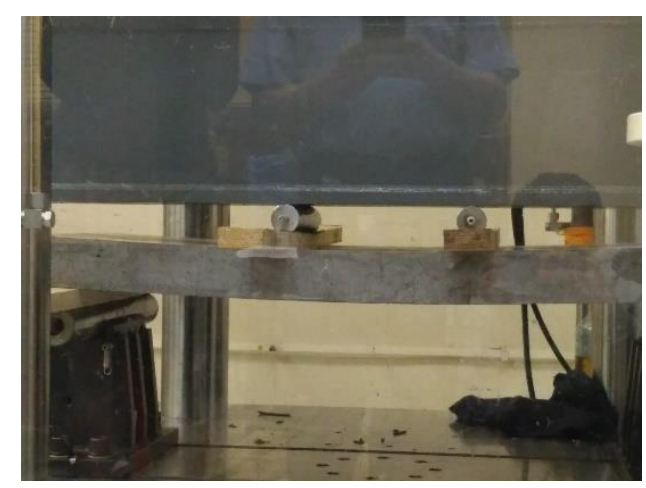

Fig.2. Tests of the plate on the testing machine BISS MAGNUM UT-05-3000.

As a result of the tests, the following characteristics of the building block were determined:

- true average density, $\mathrm{t} / \mathrm{m}^{3}$ - 1.6 (class of combustibility "NG", concrete density 1.55 $\mathrm{g} / \mathrm{cm}^{3}$, strength $45 \mathrm{MPa}$, density of reinforcement elements $1.9 \mathrm{~g} / \mathrm{cm}^{3}$ );

- bearing capacity with a thickness of $80 \mathrm{~mm}, \mathrm{t} / \mathrm{m}^{2}-1.0$;

- operational resource, years - 60 (min).

Also during the test the need to replace fiberglass reinforcement elements with other types of fiber-filled composites was established, because even despite the fact that the structure showed good results during the tests, the typical problems of rod polymer composite rebar were obvious. This is a low temperature resistance and various coefficients of temperature expansion of the polymer composite and concrete.

\section{Methods}

At present, the sequence of works is proposed:

1. Selection and optimization of the formulation of fire-resistant inorganic binder for the formation of the matrix of new nanocomposite rebar based on inorganic geopolymers.

2. Modernization of production lines for production of composite rebar. It provides for a minimal change, but allows the introduction of binder modifiers in the form of multilayer polyhedral fulleroid type of nanoparticles of toroidal form - astralenes, either at the stage of preparation of the binder, or dosed introduction into technological containers as part of process equipment;

3. Development of industrial technology for the production of nanocomposite fireresistant rebar.

4. Development the constructions of the fire-proof composite rebar for the new kind railways aleepers.

\section{Railway aleepers construction and technology}

The railway aleepers have to include into it construction some arming reburs, which have to improve the strength of these aleepers. And it is very important on a finishing stage to have a construction of the aleepers have to be corrosive protected and fire resistant. For this purposes the non corrosive and non firing composite reburs was suggested.

\section{Results and Discussion}


Developed binders can rid the polymer reinforcement from all its drawbacks. Nanocomposite rebar has high fire resistance, heat resistance and high elastic modulus. The production of reinforcing bars does not require large investments - the base pultrusion line costs about 25 thousand euros and has a capacity of more than 100 meters per hour. The FPR long ago penetrated not only into the retail segment of sales, but also into road construction and the foundations construction. The next logical step of its development (nanocomposite rebar) will be based on the already established production infrastructure. As support, additions to the current GOST on a fiber-reinforced plastic rebar should be developed. As support, manufacturers of new rebar should develop additions to the current GOST on fiber-reinforced plastic rebar. Thus, the new products will penetrate the construction market by replacing the existing fiber-reinforced plastic rebar. Th e outgoings of bringing a new product to the markets will be significantly reduced. At the same time, all the basic qualities of FRP will be preserved. The new rebar will be just as popular due to the low weight and lower overall construction cost estimates. Application area FRP will expand. Low logistical costs (small weight), the possibility of rapid deployment of production in the immediate vicinity of a large construction site - these advantages will have a significant effect on reducing the overall cost of construction.

The railway aleepers, based on the new kind of the fire proof composite rebars was developed, have produced (the model samples) and have tested.

\section{Conclusions}

An analysis of existing production technologies for fiber-reinforced plastic rebar has been made. Technology with minimal expenses for its realization is selected. The new composite rebar on the mineral binder is technologically realizable. The realization of this technology is possible due to the development of new technical solutions with the use of astralenes and inorganic materials. The very bright example of the fire resistant rebar construction for the railway aleeps was suggested.

\section{Acknowledges}

This paper was financially supported by the Ministry of Education and Science of the Russian Federation on the program to improve the competitiveness of Peoples' Friendship University of Russia (RUDN University) among the world's leading research and education centers in the 2016-2020.

\section{References}

1. M. Inman, E.R. Thorhallsson, K. Azrague, A Mechanical and Environmental Assessment and Comparison of Basalt Fibre Reinforced Polymer (BFRP) Rebar and Steel Rebar in Concrete Beams, Energy Procedia. 111 (2017) 31-40.

2. J. Sim, M. Ju, K. Lee, Thirty Years Researches on Development for Sustainable Concrete Technology, MATEC Web Conf. 138 (2017) 10.

3. V.I. Travush, D.V. Konin, A.S. Krylov, Strength of composite steel and concrete beams of high-performance concrete, Mag. Civ. Eng. 79 (3) (2018) 36-44.

4. V.I. Travush, D.V. Konin, A.S. Krylov, Strength of reinforced concrete beams of highperformance concrete and fiber reinforced concrete, Mag. Civ. Eng. 77 (1) (2018) 90100.

5. A.I. Kirsanov, O.N. Stolyarov, Mechanical properties of synthetic fibers applied to concrete reinforcement, Mag. Civ. Eng. 80 (4) (2018) 15-23. 
6. A.S. Rassokhin, A.N. Ponomarev, O.L. Figovsky, Silica fumes of different types for high-performance fine-grained concrete, Mag. Civ. Eng. 78 (2) (2018) 151-160.

7. T.A. Nizina, A.N. Ponomarev, A.S. Balykov, D.I. Korovkin, Multicriteria optimisation of the formulation of modified fine-grained fibre concretes containing carbon nanostructures, Int. J. Nanotechnol. 15 (4-5) (2018) 333-346.

8. R.B. Orlovich, V.V. Bespalov, V.N. Derkach, Compressed-bent masonry walls reinforced with composite materials, Mag. Civ. Eng. 79 (3) (2018) 112-119.

9. A.R. Emparanza, R. Kampmann, F. De CasoBasalo, State-of-The-practice of frp rebar global manufacturing, in: CAMX 2017 - Compos. Adv. Mater. Expo, 2017.

10. A. Bahari, B. Nikoufar, FRP composites in fabrication, rehabilitation and strengthening of structure, in: Proc. 6th Int. Spec. Conf. Fibre Reinf. Mater., 2017: pp. 67-70.

11. B. Benmokrane, A.H. Ali, Durability of FRP rebars in aggressive environments, in: Proc. 8th Int. Conf. Fibre-Reinforced Polym. Compos. Civ. Eng. CICE 2016, 2016: pp. $3-10$.

12. A. Rolland, M. Quiertant, A. Khadour, S. Chataigner, K. Benzarti, P. Argoul, Experimental investigations on the bond behavior between concrete and FRP reinforcing bars, Constr. Build. Mater. 173 (2018) 136-148.

13. V.G. Khozin, A.R. Gizdatullin, Collaboration of polymer composite reinforcement and cement concrete, in: J. Phys. Conf. Ser., 2018.

14. V.K.R. Kodur, P.P. Bhatt, A numerical approach for modeling response of fiber reinforced polymer strengthened concrete slabs exposed to fire, Compos. Struct. 187 (2018) 226-240.

15. M.H. Jamalan, D.F. Fu, Numerical Analysis on Bond Strength of FRP Re-bars under Elevated Temperature, IOP Conf. Ser. Mater. Sci. Eng. 371 (2018) 12-13.

16. F.M. Özkal, M. Polat, M. Yağan, M.O. Öztürk, Mechanical properties and bond strength degradation of GFRP and steel rebars at elevated temperatures, Constr. Build. Mater. 184 (2018) 45-57.

17. G. Li, J. Zhao, Z. Wang, Fatigue Behavior of Glass Fiber-Reinforced Polymer Bars after Elevated Temperatures Exposure, Materials (Basel). 11 (6) (2018) 10-28.

18. R.J.A. Hamad, M.A. Megat Johari, R.H. Haddad, Mechanical properties and bond characteristics of different fiber reinforced polymer rebars at elevated temperatures, Constr. Build. Mater. 142 (2017) 521-535.

19. F.O.L. Kudryavtsev P.G., Heat-resistant inorganic binders, Nanotechnologies Constr. 9 (2) (2017) 66-81.

20. A.N. Ponomarev, M.E. Yudovitch, M.V. Gruzdev, V.M. Yudovitch, Teoretical Estimation of Topological Factor in Interaction of the Non-Metallic Nanoparticles with Electromagnetic Waves, J. Sci. Technol. Advantages. 11 (3) (2009) 20-26.

21. A.I. Shames, E.A. Katz, A.M. Panich, D. Mogilyansky, E. Mogilko, J. Grinblat, V.P. Belousov, I.M. Belousova, A.N. Ponomarev, Structural and magnetic resonance study of astralen nanoparticles, Diam. Relat. Mater. 18 (2-3) (2009) 505-510.

22. A.I. Shames, I. Felner, V.Y. Osipov, E.A. Katz, E. Mogilko, J. Grinblat, A.M. Panich, V.P. Belousov, I.M. Belousova, A.N. Ponomarev, Closed n-Electron Network in Large Polyhedral Multi-Shell Carbon Nanoparticles, Nanosci. Nanotechnol. Lett. 3 (2011) 41-48.

23. Gravit, M.V., Nedryshkin, O.V., Ogidan, O.T. Mag. Civ. Eng. 77 (1), pp. 38-46. (2018)

24. A.V. Bushmanova, D.K. Kharchenko, K.S. Semenov, Yu.G. Barabanshchikov, V.K. Korovina, A.V. Dernakova, Mag. Civ. Eng., 79 (3), pp. 45-53. (2018)

25. Alexander, B., Vladislav, B., Journal of Physical Education and Sport (2016)

26. A.B. Elakov, R.A. Turusov, E.A. Bogachev, A.Yu. Sergeev. St. Petersburg polytechnic university journal of engineering science and technology, 24(02), 149-160 (2018) 